\title{
EMPLOYMENT AND EMPLOYABILITY FOR PHARMACOLOGY GRADUATES
}

\section{Employment prospects are exciting for graduate pharmacologists who maintain their employability in a changing work environment.}

Professor Ian Hughes, Professor of Pharmacology, Learning and Teaching Support Network (LTSN) Centre for Bioscience, School of Biomedical Sciences, University of Leeds, UK. e-mail:

i.e.hughes@leeds.ac.uk
"Students should be studying because they love their discipline" and "Degree courses are there to provide an appropriate workforce". Each of these statements has its adherents, but it is generally appreciated that degree courses supported by the tax payer should contribute to the provision of a well-qualified and creative workforce that can make a contribution to wealth generation and the economic future of a country. Pharmacology graduates have made an outstanding contribution to the success of the international pharmaceutical industry, which employs more than 1.5 million people, has made an enormous contribution to the overseas earnings of some countries and has improved the human situation by developing effective treatments for major diseases. Graduate-level pharmacologists have traditionally originated from medical and pharmacy courses, and (especially in the United Kingdom) from specialist pharmacology degrees that have recently expanded substantially. Pharmacology courses that used to enrol 8-15 students now enrol $50-100$ per year; more universities provide pharmacology degrees, and combined pharmacology degrees have been extensively developed. There is no shortage of graduates who have pharmacological training. The question is more whether they meet the needs of their employers.

Thirty years ago, $>90 \%$ of first-degree pharmacologists went on to work within the pharmaceutical industry or do a higher degree related to pharmacology. Now, less than half of pharmacology graduates from some institutions take jobs that use their specific pharmacological knowledge. The breadth of student aspirations in employment and the diversity of employers have increased enormously. Even within the pharmaceutical industry, pharmacologists can be found not only in laboratory-based research and development (R\&D), but also in information science, product licensing, regulatory affairs, product management, sales and marketing, clinical research and trials, safety (toxicology), finance, post-marketing surveillance, business development and portfolio management.

Most studies show that the diverse employers of pharmacology graduates are nevertheless looking for similar aspects in an employee. Communication skills, flexibility, application, problem-solving ability, attention to detail, tenacity, team-working skills, an ability to learn, information technology (IT) skills, including information retrieval and analysis, creativity and professionalism are high on the priority list. Particularly important is the completion of a 'sandwich year' or other work experience, and laboratory-based jobs need a proven commitment, aptitude and enthusiasm for lab work. Although subjectspecific knowledge and skills are important, they are useless alone, and in appreciation of this, there has been a change in the curriculum in pharmacology degrees to include the explicit teaching, recognition and reward of the above aspects.

For pharmacology graduates who meet the requirements of the industry, employment prospects are bright. Many big pharma companies continue to expand their $R \& D$ activities, and a host of smaller enterprises exploit particular aspects of bioscience that impinge on drug discovery and development. However, jobs today are characterized by transience and change. Excluding Ph.D. students, a small survey indicates that $71 \%$ of graduates in first employment have changed their jobs within three years. Graduates need to be positioned correctly (through life-long learning and continuing development) to maximize their desirability to future employers. Focusing on 'employability' cannot begin too early, and students need to look outside their degree course and develop skills during part-time or vacation employment and other extra-curricular activities. As the intake of new employees in big pharma tends to show considerable peaks and troughs, graduates need to be able to bridge years that have few opportunities with alternative employment that will enhance their employability in their desired career when opportunities do arise. Those students wishing to do a higher degree in pharmacology need to bear in mind that having a postgraduate degree does not guarantee a job for life. In addition to subject expertise, industry still requires the skills discussed above and is also looking for leadership, creativity and an ability to manage others.

With regard to subject-specific knowledge and skills, most pharmacology courses now incorporate aspects of molecular biology and molecular pharmacology along with traditional material, but there is a current dearth of graduates who have integrative pharmacological abilities and in vivo skills. Schemes are now operating in several countries to counteract this shortfall. For instance, some pharma companies are offering sponsorships to students to study in vitro pharmacology, and the British Pharmacological Society, in conjunction with the UK pharmaceutical industry, now provides financial assistance to university departments to increase or maintain in vivo components in their courses. This shows that universities can be responsive to employers needs, but employers must recognize the significant lag time inherent in the system of course change, the implications of rapidly changing employer needs and the diversity of employers of pharmacology graduates.

In summary, pharmacology graduates who use careerplanning skills to maintain their employability in an evolving workplace will find satisfying employment in challenging, fast-moving and exciting posts throughout their working lives.

Professor Ian Hughes 